\title{
Bimatoprost in the treatment of eyelash hypotrichosis
}

This article was published in the following Dove Press journal:

Clinical Ophthalmology

13 April 2010

Number of times this article has been viewed

\author{
Simon K Law \\ Jules Stein Eye Institute, University \\ of California, Los Angeles, \\ California, USA
}

Correspondence: Simon K Law 100 Stein Plaza \#2-235, Jules Stein Eye Institute, Los Angeles, CA 90095, USA $\mathrm{Tel}+\mathrm{I}$ (3I0) 794-I477

Fax +I (3I0) 206-7773

Email law@jsei.ucla.edu
Abstract: Eyelashes hypotrichosis is a condition indicated by an inadequate amount of eyelashes. Hypertrichosis of eyelashes, characterized by excessive eyelash growth, is a regular phenomenon associated with ophthalmic prostaglandin and prostamide analogs. Recently, the US Food and Drug Administration approved Latisse ${ }^{\circledR}$ (bimatoprost $0.03 \%$ solution), identical to the ophthalmic solution for glaucoma treatment, for increasing eyelash length, thickness and darkness in patients with hypotrichosis of the eyelashes. When prostaglandin and prostamide analogs interact with the prostanoid receptors in the hair follicle, this most likely stimulates the resting follicles (telogen phase) to growing follicles (anagen phase). Prostaglandin and prostamide analogs may also prolong the anagen phase of eyelashes, leading to an increase of eyelash length. Although bimatoprost is effective in promoting increased growth of healthy eyelashes and adnexal hairs, its effectiveness in patients with eyelash alopecia areata is debatable and its protective effect is not yet studied in patients with eyelash loss secondary to radiation or chemotherapy. Bimatoprost is generally safe when applied to the base of the eyelashes at the lid margin with minimum side effects. However, other ocular or systemic side effects associated with ophthalmic prostaglandin and prostamide analogs may occur when instilled on the surface of the eye, and patients must be informed and monitored.

Keywords: bimatoprost, Latisse, prostaglandin, prostamide, eyelash, hypotrichosis

\section{Introduction}

Hypotrichosis is characterized by a less than normal amount of hair, and eyelashes hypotrichosis is the term for an inadequate amount of eyelashes. Eyelashes provide a natural protective barrier for the eyes from sunshine, wind, foreign bodies, and perspiration. They perform a similar function to the whiskers on a cat or a mouse. They are sensitive to the touch and provide a warning when an object is near the eye, which in turn prompts the eye to close reflexively. ${ }^{1}$

In addition to the protective purpose of the eyelash, a more contemporary goal for eyelash length and thickness in modern humans is cosmetic attraction. Eyelashes frame the eyes together with the eyebrows, hairline, cheekbones, nose, lips and chin to create a facial appearance that is unique to every individual. The absence of eyelashes removes one of the salient anatomical features associated with a normal facial appearance. ${ }^{1}$ Long eyelashes are also considered a sign of femininity and beauty in most if not all cultures.

Causes of eyelashes hypotrichosis are many, including hereditary, aging, chemotherapy, other medical treatment and unknown causes. Physical trauma involving the face, eye surgery and trichotillomania may also cause thin or absent lash growth. ${ }^{2,3}$ 
Since the introduction of latanoprost in 1996 as an ocular hypotensive agent for the treatment of glaucoma, hypertrichosis of eyelashes has been reported as a regular phenomenon associated with ophthalmic prostaglandin and prostamide analogs. ${ }^{4,5}$ When compared to latanoprost in clinical study, ophthalmic bimatoprost $0.03 \%$ was found to have an even higher occurrence of eyelash growth. ${ }^{6-9}$ Recently, Latisse ${ }^{\circledR}$ (Allergan Inc. Irvine, CA) which is bimatoprost $0.03 \%$ solution and identical to the ophthalmic solution for glaucoma treatment, was approved by the US Food and Drug Administration (FDA) for increasing eyelash length, thickness and darkness in patients with hypotrichosis of the eyelashes. In this article, bimatoprost is reviewed in terms of its pharmacology, efficacy, and safety in the treatment of eyelash hypotrichosis. Although this review primarily focuses on bimatoprost, it is necessary to discuss the effects of other prostaglandin analogs on eyelashes, particularly latanoprost, which has been more extensively studied in hypertrichosis of eyelashes. Latanoprost and bimatoprost also share many similarities both structurally and pharmacologically.

\section{Pharmacology \\ Human eyelash characteristics}

Human have 90 to 160 eyelashes in the upper eyelid and 75 to 80 in the lower eyelid, with great variation of length. ${ }^{10,11}$ The lashes typically originate from the anterior lamella of the eyelid where they lie on the tarsal plate. They grow in imperfect rows of 5 to 6 in the upper lid and 3 to 4 in the lower lid in Caucasians. ${ }^{12,13}$ An eyelash is terminal hair, which is coarse, medullated, long and pigmented. In comparison, vellus hair, which is often found on a woman's face, is soft, unmedullated, short and non-pigmented. Eyelashes have the widest diameter of body hairs and are the most pigmented of the terminal hairs. ${ }^{14}$

Hair follicles have a unique cyclical behavior pattern and the entire cycle varies in duration depending on the location in the body. Each human eyelash lives an average of 3 to 6 months. ${ }^{13,15}$ The growth phase (anagen) of the eyelash hair follicle and eyelash lasts for approximately 30 days. At the end of the eyelash growth period, a brief transition stage (catagen) of 15 days follows, with shortening of the hair follicle. Finally, the follicle enters a resting phase (telogen) of about 100 days, leading to the detachment of the eyelash. ${ }^{10,13,16-18}$ The proportion of follicles in telogen is normally higher in eyelashes than scalp hairs. One study estimated 59\% to $85 \%$ of eyelash follicles are in telogen phase, depending on whether they are on the upper or lower lid. ${ }^{18}$
The length of an eyelash can vary greatly, from 8 to $12 \mathrm{~mm}$ in the upper lid and from 6 to $8 \mathrm{~mm}$ in the lower lid, and depends on the ethnicity of the individual. ${ }^{10,11}$ Eyelash follicle growth rate is also quite variable, with an average of 0.12 to $0.14 \mathrm{~mm}$ daily. ${ }^{11,13}$ All eyelashes are characterized by a tendency to bend from the bulb to the top of the shaft. ${ }^{13}$ The degree of curvature depends on ethnic origin. ${ }^{11}$ Interestingly, eyelashes do not turn grey with aging, or only at a very late stage. ${ }^{10}$

Several factors are involved with hair follicle growth and cycling but their effects on eyelash growth are unclear. Androgens are the principal hormones that control sexual hair growth by receptors localized in the dermal papilla, but eyelashes do not seem to be as sensitive. ${ }^{19,20}$ Retinoic acid derivatives affect the hair growth cycle in mice by increasing the length of the anagen phase, and insulin-like growth factorI slows the hair cycle entry in the catagen phase. Growth hormone, insulin, glycocorticoids, and prolactin are also implicated, but there is no evidence to support an involvement of these hormones in eyelash growth. ${ }^{17}$

\section{Prostamides metabolism}

Bimatoprost is a synthetic product initially designed pharmacologically to reduce the intraocular pressure (IOP) for the treatment of glaucoma. It is structurally similar to the other prostaglandin $\mathrm{F}_{2 \alpha}\left(\mathrm{PGF}_{2 \alpha}\right)$ analogs, including latanoprost, travoprost and unoprostone, but has an ethyl amide instead of an isopropyl ester at the C-1 carbon of the alpha chain. Bimatoprost has been proposed to be similar to a class of naturally occurring fatty acid amides otherwise known as "prostamides" (prostaglandin ethanolamides). ${ }^{21,22}$

Prostamides are recently identified as a unique class of compounds that are formed from anandamide catalyzed by cyclooxygenase-2 (COX-2). Anandamide is one of the naturally occurring mammalian endogenous cannabis-like ligands (endocannabinoids) derived from arachidonic acid.

The biosynthesis of anandamide consists of two steps of enzymatic reactions: (1) formation of the membrane glycerophospholipid precursor, $\mathrm{N}$-arachidonoylphospharidylethanolamide (NArPE), by the transfer of a fatty acyl chain from the sn-1 position of glycerophospholipids to the amino group of pho sphatidylethanolamine, (2) enzymatic hydrolysis of NArPE catalyzed by a N-acylphophatidylethanolamides selective phospholipase D (NAPE-PLD) to form anandamide. ${ }^{23}$ After synthesis, anandamide is rapidly inactivated via a tightly controlled series of events involving sequestration 
by cells and enzymatic hydrolysis of its amide bond to arachidonic acid and ethanolamide. ${ }^{24}$ With the presence of an arachidonate moiety in their chemical structure, anandamide and another endocannabinoid, 2-arachidonoylglycerol (2-AG) are substrates for enzymes of the arachidonate casade including COX-2, but not COX $-1 .^{25}$ Similar to the conversion of arachidonic acids to prostaglandins by $\mathrm{COX}$ and prostaglandins synthase, $\mathrm{COX}-2$ converts anandamide to the endoperoxide intermediates prostamide $\mathrm{G}_{2}\left(\mathrm{PMG}_{2}\right)$ and prostamide $\mathrm{H}_{2}\left(\mathrm{PMH}_{2}\right)$, which are then converted by specific prostaglandins synthases to the various prostamides. ${ }^{26}$ However, unlike anandamide, prostamides do not possess cannabimimetic and related activity, and their physiological actions have not been fully investigated.

Synthetic prostamide analog, bimatoprost, and prostaglandin $\mathrm{F}_{2 \alpha}$ analogs, such as latanoprost, travoprost and unoprostone are effective ocular hypotensive agents. The mechanism of IOP reduction involves secretion of metalloproteinases by ciliary smooth muscle cells and remodeling of the extracellular matrix, the resulting widening of intermuscular spaces, and ultimately an increase of uveoscleral outflow of aqueous. Although prostamides are structurally similar to prostaglandins, they exhibit no meaningful activity at prostanoid receptors. ${ }^{26}$ Experimental evidence suggests that prostamides may act as endogenous ligands at their own receptors (prostamide receptors). Nevertheless, prostamide activity has not been demonstrated in the absence of prostanoid receptor activity. ${ }^{26}$

In a recent study, Liang at al identified 6 splicing variants of prostanoid FP receptor mRNA in human ocular tissues. ${ }^{27}$ Immunoprecipitation analysis further confirmed that the FP receptor is dimerized with FP receptor variant-4 (altFP4). It appears that the FP-altFP4 heterodimer maintains responsiveness to $\mathrm{PGF}_{2 \alpha}$ and its analogs and acquires sensitivity to bimatoprost. It was also found that $\mathrm{PGF}_{2 \alpha}$ and bimatoprost has a different calcium mobilization profile. $\mathrm{PGF}_{2 \alpha}$ elicited a rapid increase in intracellular calcium followed by a steady state phase. In contrast, bimatoprost elicited an immediate increase in intracellular calcium followed by a second phase, and the prostamide antagonist, AGN211335, selectively and dose-dependently inhibited the bimatoprost-initiated second phase, but did not block the action of $\mathrm{PGF}_{2 \alpha}$. Novel ligand-recognition sites may have emerged as a result of prostanoid-prostanoid receptor hererodimerization, and FP-altFP complexes may represent the underlying basis of bimatoprost pharmacology on IOP. ${ }^{27}$ It remains to be proven if this receptor heterodimerization is also responsible for the action of bimatoprost on eyelash growth.

\section{Hair growth induced by prostaglandins and prostamides}

Prostaglandins are probably involved in a specific and complex network in hair growth and differentiation control. Most of the hair cell types are endowed with prostaglandin metabolism machinery and are able to produce $\mathrm{PGE}_{2}$ and/or $\mathrm{PGF}_{2 \alpha}$; and all prostaglandin receptors are present in hair follicle. ${ }^{28-30}$ The epithelial part of the hair bulb was identified by immunohistology and enzyme-linked immunosorbent assays as the main source of prostaglandin synthesis and interconversion. ${ }^{28}$ Both the $\mathrm{F}$ series and E series prostaglandins may have an effect on hair growth. ${ }^{31}$ Inhibitors of prostaglandin endoperoxide synthase such as indomathacin, ibuprofen, and aspirin were shown to block prostaglandin synthesis and inhibit hair growth. ${ }^{32,33}$ Minoxidil, a known hair growth agent, was reported to activate activity of purified COX-1, suggesting a positive role of prostaglandin in hair growth onset. ${ }^{34}$ Latanoprost, a $\mathrm{PGF}_{2 \alpha}$ analog, was found to be able to promote hair regrowth in $\mathrm{C} 57 / \mathrm{B} 16$ mouse model. ${ }^{35} \mathrm{PGF}_{2 \alpha}$ and $\mathrm{PGE}_{2}$ were reported to have hypertrichotic effects on mice. ${ }^{36} \mathrm{PGF}_{2 \alpha}$ and prostaglandin $\mathrm{F}$ receptor analogs were able to induce telogen to anagen transition. Similar effects were found on stump-tailed macaque. ${ }^{37}$

Although prostaglandin metabolism machinery and prostaglandin receptors are present in hair follicle, the mechanisms by which prostaglandins and prostamides trigger eyelash growth are not clear. So far, this area of research is limited to prostaglandin analogs, or specifically, latanoprost. It is suggested that hypertrichosis following administration of prostaglandin analogs is probably a result of the induction of the anagen phase in telogen phase follicles of eyelashes. ${ }^{15}$ Prostaglandin analogs may also prolong the anagen phase of eyelashes, leading to an increase of eyelash length. ${ }^{38}$ The increased anagen duration has been hypothesized to be determined at the initiation of the anagen phase and is probably controlled by the dermal papilla. ${ }^{39}$ In a study to determine the minimum interval of latanoprost exposure necessary to cause hypertrichosis of eyelashes, brief exposure to latanoprost ( $<22$ days) was associated with hypertrichosis similar to those following sustained exposure. The effect persisted to some degree throughout the duration of a follow-up interval of 14 months. ${ }^{15}$ The author suggested that a program is initiated to trigger the anagen phase of the hair cycle in the follicles of eyelashes 
and that this program is able to proceed in the absence of an ongoing stimulus. ${ }^{15}$

\section{Efficacy}

\section{Hair growth associated with prostaglandin and prostamide analogs}

Increase of hair growth is regularly associated with ophthalmic application of different prostaglandin and prostamide analogs in patients of different ethnicities and age groups. In a series of 317 patients, Demitsu et al reported latanoprost-induced hypertrichosis in $77 \%$ of patients. ${ }^{40}$ In Japanese patients receiving ophthalmic latanoprost treatment for its ocular hypotensive effect, increased vellus hair of the lid was noted in $37.6 \%$ and hypertrichosis of eyelashes was noted in $50.5 \%$ of patients. ${ }^{41}$ In a study to compare the eyelash lengthening effect of latanoprost in adults and children with glaucoma, Elgin et al found that the mean difference in eyelash lengths at baseline and the sixth month was $0.67 \pm 0.09 \mathrm{~mm}$ in adults and $0.75 \pm 0.25 \mathrm{~mm}$ in children. ${ }^{42}$ After taking travoprost $0.004 \%$ for 12 months, changes in eyelashes, including increased length, thickness, density, and color, were reported in $57 \%$ of patients. ${ }^{43}$ Eyelash growth has been reported in $12.6 \%$ to $35.7 \%$ of patients during clinical trials of bimatoprost $0.03 \%$.

In a 3-month bimatoprost versus latanoprost trial, eyelash growth was more common in the bimatoprost group (13\% bimatoprost vs. 4\% latanoprost). ${ }^{6}$ Hypertrichosis appears to occur earlier during bimatoprost treatment as compared to latanoprost. This may be because of the possibility that bimatoprost, unlike latanoprost, does not need to be converted into an active metabolite in order to extend potent pharmacological activity. Another possible explanation is that bimatoprost sensitivity may be conferred by interacting with FP-altFP heterodimer receptor instead, and the additional secondary calcium signaling pathway elicited by bimatoprost may translate into a stronger response of hair growth.

Bimatoprost seems to be able to increase the length of the eyelash more than latanoprost. In an unpublished randomized vehicle-controlled, multicenter, clinical trial, 278 patients were assigned to apply either one drop of bimatoprost $(n=137)$ or vehicle only $(n=141)$ to the upper eyelid margin at the base of the eyelashes once nightly for 16 weeks. ${ }^{46}$ Eyelash prominence, measured primarily by length but also by thickness and darkness, was rated using a 4-point Global Eyelash Assessment scale developed by the manufacturer. An increase in the scale occurred in $78 \%$ ( $\geq 1$ grade) and $32.8 \%$ ( $\geq 2$ grades) on bimatoprost compared to $18 \%$ and $1.4 \%$ in the vehicle group, respectively. In the bimatoprost group, eyelash length increased an average of $1.4 \mathrm{~mm}(25 \%)$ compared to $0.1 \mathrm{~mm}(2 \%)$ in the vehicle group after 16 weeks of treatment. ${ }^{46}$ In a prospective study assessing the effect of eyelash growth in the ipsilateral eyelids of patients treated with unilateral ophthalmic latanoprost for glaucoma, Johnstone documented an average increase of $19.5 \%$ in eyelash length with mean treatment duration of 20 weeks. ${ }^{4}$

The FDA has approved bimatoprost in a $0.03 \%$ solution for increasing eyelash length, thickness and darkness in patients with hypotrichosis of the eyelashes. For eyelash enhancement, one drop of bimatoprost $0.03 \%$ solution is placed on a single-use applicator and applied to the upper eyelid margin along the roots of the eyelashes once nightly; a new applicator should be used for each eye.

\section{Characteristics of eyelashes in the presence of prostaglandin and prostamide analogs}

Hypertrichosis is a regular seen side effect in eyes treated with ophthalmic prostaglandin and prostamide analogs. In a prospective study of 43 patients who were unilaterally treated with latanoprost, researchers identified a number of characteristics of eyelashes treated with latanoprost. ${ }^{4}$ After treatment, eyelashes increased in length, thickness, and pigmentation. The number of eyelashes also increased in preexisting lash rows and in areas of transition between the terminal lashes along the lash line and the vellus hairs of the skin. These hairs had a more robust appearance, were longer, thicker, and more heavily pigmented, and arose at a more acute angle from the skin than in the control eye. The vellus and intermediate hairs had transformed into terminal hairs, and produced the appearance of new rows of terminal eyelashes in the lid margin. The changes in the appearance of the eyelashes were not limited to the lashes along the lid margin, but also affected the hairs in the medical and lateral canthal areas. ${ }^{4}$ It is reasonable to expect that all these changes may be more prominent and obvious in bimatoprost treatment. The clinically observable eyelashes hypertrichosis resolved following discontinuation of latanoprost or bimatoprost. ${ }^{4,46}$

Even brief exposure to an ophthalmic prostaglandin analog appears to be associated with eyelash change. Johnstone reported that a very brief exposure to latanoprost could produce a similar effect of eyelash growth as compared to chronic exposure. ${ }^{15}$ However, the hypertrichosis had a marked irregular pattern of lash curling. The author postulated 
that the differences in appearance of eyelashes and pattern of eyelash growth between brief exposure and sustained exposure to prostaglandin analogs may be secondary to a lack of uniform penetration into the hair follicle leading to asymmetric development of the follicle and inner root sheath. Some patients were also found to have persistent trichomegaly up to 14 months following a brief exposure to latanoprost. ${ }^{15}$ It is uncertain if similar characteristics of eyelash growth after brief exposure may happen to bimatoprost applied to upper eyelid margin along the roots of the eyelashes.

The hypertrichosis of eyelashes associated with prostaglandin and prostamide analogs usually occurs together with darkening of the eyelashes. However, some patients developed bilateral poliosis after using different ophthalmic prostaglandin $\mathrm{F}_{2 \alpha}$ analogs for treating primary open angle glaucoma. $^{47}$

\section{Eyelash regrowth in alopecia areata}

There are case reports of the successful use of prostaglandin analogs including latanoprost and bimatoprost in the treatment of eyelash alopecia areata. ${ }^{48-51}$ In an 11-year-old patient who had alopecia areata with bilateral loss of eyelashes, Mehta et al reported a successful regrowth of the eyelashes after cutaneous treatment with latanoprost. ${ }^{51}$ Minimal lash growth was noted on all four lids 4 weeks after application of latanoprost once daily, and pronounced lash growth was noted in 8 weeks. Treatment was then altered to once a week and the number of eyelashes was maintained over the next 6 months. ${ }^{51}$

However, lack of efficacy of topical latanoprost and bimatoprost ophthalmic solutions in promoting eyelash growth in patients with alopecia areata has also been reported..$^{52}$ In a 16-week, randomized, investigator masked, controlled study, 11 patients with alopecia areata and greater than $50 \%$ bilateral eyelash loss were randomized to receive an application of either latanoprost or bimatoprost to the upper and lower eyelid margins of one eye only. No appreciable eyelash regrowth was noted on clinical assessment of eyelid margins or on review of digital photographs after 16 weeks. Authors questioned whether ocular instillation of prostaglandin analogs used in glaucoma treatment may be more effective in stimulating eyelash growth. ${ }^{52}$ In patients without eyelashes, it may be difficult to keep the cutaneously applied medication on the lid margin for adequate penetration into the hair follicles. It is also possible that irreparable damage to the follicle stem cells in some patients may have led to irreversible hair loss.

In another prospective study of similar design with bimatoprost $0.03 \%$ solution instilled on the eye, 7 patients (11 patients enrolled, 7 completed the study) with eyelash alopecia areata with greater than 50\% bilateral eyelash loss received bimatoprost solution once daily to one eye, while the untreated eye served as the control. ${ }^{49}$ Bimatorpost was found to be ineffective in promoting eyelash growth in 5 patients with $95 \%$ or greater eyelash loss caused by alopecia areata. However, in 2 patients with $30 \%$ and $40 \%$ eyelashes present at baseline, some bilateral eyelash growth was noted. ${ }^{49}$ Another prostaglandin analog, travoprost, has also been studied in eyelash alopecia areata. Growth of eyelashes was observed in only 1 out of 3 patients, whereas all three developed increased pigmentation of the eyelid skin. ${ }^{53}$ It seems that prostaglandin or prostamide analogs are only effective in promoting eyelash regrowth in patients with a mild form of eyelash alopecia areata.

\section{Eyelashes regrowth in other causes of hypotrichiasis}

Prostaglandin analogs, not prostamide, have been studied in animal model of hair injury associated with radiation therapy and chemotherapy. Prostaglandin $\mathrm{E}_{2}\left(\mathrm{PGE}_{2}\right)$ analog was shown to have a significant degree of protection against radiation-induced or doxorubicin-induced alopecia in mice. ${ }^{54-56}$ This protective effect has yet to be studied in human undergoing radiation therapy or chemotherapy.

\section{Safety \\ Side effects of ophthalmic prostaglandin and prostamide analogs}

Prostaglandin and prostamide analogs have been associated with similar systemic and local side effects when administered topically on the surface of the eye as an ocular hypotensive agent for glaucoma. When bimatoprost is applied to the eyelashes and lid margins in very close proximity to the surface of the eye to promote growth of the eyelash, potential side effects may occur if the medication is administered inappropriately on the surface of the eye.

Ophthalmic use of prostaglandin analogs and bimatoprost is known to be associated with increase iris pigmentation. Iris darkening may be due to increase of melanin granule size secondary to an induced heightened melanogenesis. ${ }^{57,58}$ Older patients may have more iris color change when topical prostaglandin is used. ${ }^{59}$ Patients with hazel irises that have mixed coloring are at higher risk of iris darkening, whereas homogenous blue or brown irises have relatively little likelihood of getting induced iris darkening. ${ }^{60}$

Conjunctival hyperemia is associated with ophthalmic prostaglandin analogs and bimatoprost. It is the most 
common adverse event associated with bimatoprost $0.03 \%$ as ophthalmic therapy for glaucoma, which occurred in $42 \%$ to $46 \%$ of patients. ${ }^{6,44,45}$ Approximately $1 \%$ to $4 \%$ of patients discontinued treatment with bimatoprost $0.03 \%$ because of conjunctival hyperemia. ${ }^{44,45}$ Comparing with latanoprost, bimatoprost has significantly more conjunctival hyperemia and increased eyelash growth reported, but headaches were more commonly reported with latanoprost. ${ }^{6-8,61,62}$

Increase of pigmentation of the periocular skin is seen with ophthalmic prostaglandin analogs or bimatoprost therapy. The increase of pigmentation is caused by increased melanogenesis without melanocyte proliferation or inflammation. ${ }^{63}$ This side effect occurs more frequently with bimatoprost than latanoprost. Wiping the lid was found to help decrease the hyperpigmentation when a topical drop is used. ${ }^{64}$ Patients are advised to blot off any solution that drips from the treated area.

Deepening of the eyelid sulcus, periorbital fat atrophy, and relative enophthalmos have been reported with ophthalmic travoprost and bimatoprost used in treatment of glaucoma. ${ }^{65-68}$ In some patients the disparity of periorbital appearance between the treated eye and the fellow eye returned to normal after discontinuation of the ophthalmic prostaglandin analogs or prostamide for a relatively long interval. ${ }^{66,68}$ The exact mechanism is uncertain, but fatty degeneration and reduced collagen fibers in the levator complex caused by the prostaglandin or prostamide analogs have been proposed as a possible mechanism. ${ }^{66,68}$

Anterior uveitis has been reported in patients using ophthalmic prostaglandin or prostamide analogs. ${ }^{69,70}$ Anterior uveitis has been observed in approximately $1 \%$ of patients receiving latanoprost, which resolves with corticosteroid therapy. ${ }^{71}$ Association of latanoprost and uveitis has been confirmed with a dechallenge and rechallenge method in two studies. ${ }^{72,73}$ Because of the similar efficacy and safety profile between prostaglandin analogs and bimatoprost, use of these agents is generally avoided in eyes with active inflammation.

The association of herpetic simplex viral infection and prostaglandin analogs and bimatoprost has been documented. ${ }^{74,75}$ Herpes simplex keratitis has been reported to develop after initiation of latanoprost therapy with dechallenge and rechallenge method. ${ }^{76}$ In another case report, 2 patients developed HSV dermatitis of the periocular skin after using latanoprost. ${ }^{77}$ Latanoprost has been shown to worsen acute herpetic keratitis in the rabbit eye (New Zealand white (NZW) rabbit) and increase the risk of recurrences in latently infected animals. ${ }^{78}$ However, in the Induced
Reactivation and Spontaneous Shedding HSV-1/NZW rabbit latency models, latanoprost was not found to promote ocular shedding of HSV-1. ${ }^{79}$ Use of any topical prostaglandin and prostamide analogs in patients with a history of ocular herpetic viral infection should be avoided.

Patients with active or at risk of ocular inflammation or infection should avoid using bimatoprost to promote eyelash growth.

\section{Specific safety concerns of bimatoprost used in treating hypotrichiasis}

The most common local side effects reported by subjects in the clinical trial using bimatoprost as treatment of hypotrichosis were essentially consistent with those experienced by patients using bimatoprost as a treatment in glaucoma. The most common side effects in the clinical trial were eye pruritus, conjunctival hyperemia, eye irritation, dry eye symptoms, and erythema and hyperpigmentation of the eyelids. ${ }^{46}$

Although increase of the length, thickness and darkness of eyelashes are desirable effects of bimatoprost in treatment of hypotrichosis, excessive growth and thickness of the eyelashes has been reported after using the ophthalmic solution of bimatoprost $0.03 \%$ once daily after 1 to 3 months. ${ }^{80-82}$ Patients were reported to have increased hair growth in the malar regions and external canthal area, excessive growth of eyelashes and eyebrows, and eyelid hyperpigmentation. In one patient, whose eyelash and eyebrow growth returned to normal within 2 months of stopping the ophthalmic bimatoprost treatment, the medication was restarted with instruction to thoroughly clean the ophthalmic solution drippings from her eyes. Nevertheless, after one month of reinstating the treatment, excessive growth and thickness of the eyelashes and eyebrow was again observed along with malar hypertrichosis and eyelid hyperpigmentation. ${ }^{81}$ In addition, lash ptosis and trichiasis secondary to misdirected eyelash growth have also been reported in association with latanoprost and travoprost use. ${ }^{83,84}$

Ophthalmic bimatoprost $0.03 \%$ has been reported to cause changes in the pigmentation of tissues, including pigmentation of the periocular skin. Bimatoprost-induced periocular hyperpigmentation appears between 3 to 6 months, with hyperpigmentation resolving between 3 to 12 months upon discontinuation of the drug. ${ }^{85,86}$

Increased iris pigmentation has been cited as a side effect of ophthalmic bimatoprost when used in glaucoma treatment. However, iris pigmentation changes were not noted in the clinical trial of bimatoprost used for promoting eyelash growth. This is probably because the drug was 
applied at the lid margin and the root of the eyelashes and intraocular penetration was therefore minimized. ${ }^{46}$ Since iris pigmentation change, associated with use of ophthalmic prostaglandin analog, can be permanent, patients who desire to use bimatoprost to promote eyelash growth must be informed of this possible side effect.

As mentioned above, there are patients reported to develop poliosis together with hypertrichosis when ophthalmic prostaglandin analog is used in treating glaucoma. Chen et al reported a series of 7 patients, aged 59 to 78 , who developed poliosis after prostaglandin analogs were used; including 4 patients on latanoprost, 2 patients on bimatoprost, and 1 patient on travaprost. Poliosis was noted as earlier as 6 weeks after starting treatment. ${ }^{47}$ The affected lashes were typically interspersed with normally pigmented lashes. The authors observed on several occasions that the white lashes were new, implying that the side effect may result from failure of pigmentation in newly stimulated eyelash growth or a stimulated growth of previously inconspicuous white lashes. ${ }^{47}$ A possible explanation proposed by the authors is that during the anagen phase of the hair follicle cell cycle, genetically predetermined differences in follicular response results in some dermal papillae secreting mitogens, whereas others synthesize inhibitory factors and result in varying response of hair follicles to prostaglandin analogs. ${ }^{15,47}$

The commercially available bimatoprost products (both Latisse $^{\circledR}$ and Lumigan ${ }^{\circledR}$ [also marketed by Allergan Inc.]) contain benzalkonium chloride as preservative. Ocular exposure to benzalkonium chloride may have a cytotoxic effect on human cornea in some patients, and clinically present as erosion of epithelium, irritation, foreign body sensation, and other dry eye symptoms. ${ }^{87}$

Cystoid macular edema has been reported when ophthalmic bimatoprost was used in high-risk patients (aphakia, pseudophakia with ruptured posterior capsule during surgery, history of uveitis, or retinal inflammatory or vascular disease). Cystoid macular edema developed in a patient with glaucoma therapy switched from latanoprost to bimatoprost 9 months after cataract surgery. ${ }^{88}$

\section{Systemic side effects of bimatoprost}

Systemic adverse events reported after treatment with bimatoprost $0.03 \%$ have included symptoms of common cold and upper respiratory tract infection, headaches, abnormal liver function tests, asthenia and hirsutism. Bimatoprost $0.03 \%$ did not have any clinically significant effect on heart rate or blood pressure in patients with glaucoma or ocular hypertension in clinical trials. ${ }^{45,89,90}$
Since bimatoprost is similar in structure and outcome with the other topical prostaglandin analogs, it is important to be aware of the side effects reported with the other prostaglandin analogs. There is a case report of abdominal cramps associated with travoprost confirmed by dechallenge and rechallenge procedures. ${ }^{91}$ Other systemic events, each with an incidence of 1 or $2 \%$, included chest pain/angina, muscle/ joint/back pain and rash/allergic skin reaction. Angina, arterial hypertension, and tachycardia have been anecdotally reported following latanoprost use. ${ }^{92,93}$ In a randomized study, headache was more frequent in patients receiving latanoprost than in those receiving bimatoprost although this difference did not reach statistical significance. ${ }^{6}$ Patients with no prior history of migraine and/or headache have reported migraine after receiving latanoprost treatment. ${ }^{62}$

Bimatoprost is classified as a category $\mathrm{C}$ drug according to the use-in-pregnancy ratings of the FDA. Category $\mathrm{C}$ denotes that animal reproduction studies have shown an adverse effect on the fetus, with no adequate and well-controlled studies in humans. Potential benefits of the drug, however, may warrant its use in pregnant women despite potential risks. Experience of ophthalmic prostaglandin analogs and prostamide use during human pregnancy is limited. In an observation study of 10 pregnant women exposed to latanoprost during the first trimester, 9 women delivered normal fetuses with no malformations. One pregnancy was complicated by miscarriage, which occurred 2 weeks after treatment was ended in a 46-year-old woman, primi-gravida, who had increased reproductive risk related to her advanced age. ${ }^{94}$

\section{Conclusion}

Latisse $^{\circledR}$ is identical to Lumigan ${ }^{\circledR}$ with bimatoprost $0.03 \%$ as the active ingredient. Lumigan ${ }^{\circledR}$ is marketed for reduction of elevated IOP in patients with glaucoma, while Latisse ${ }^{\circledR}$ is approved for increasing eyelash length, thickness and darkness in patients with hypotrichosis of the eyelashes. For eyelash enhancement, 1 drop of bimatoprost $0.03 \%$ solution is placed on a single-use applicator and applied to the upper eyelid margin along the roots of the eyelashes once nightly; a new applicator should be used for each eye.

Bimatoprost is a synthetic prostaglandin analog. But unlike the prostaglandin $\mathrm{F}_{2 \alpha}$ analogs such as latanoprost, travoprost and unoprostone, bimatoprost has an ethyl amide rather than an isopropyl ester at the $\mathrm{C}-1$ carbon of the alpha chain, and can be classified as a prostamide. Prostaglandin or prostamide analogs are potent agents in the reduction of elevated IOP and hypertrichosis was found to be a regular side effect. This once perceived side effect is now a desirable outcome for patients 
who prefer to have longer, thicker, and darker eyelashes. ${ }^{2}$ Clinical trial of bimatoprost for eyelash growth conducted by the manufacturer and other clinical trials using bimatoprost as a glaucoma therapy have shown that it is an effective agent in promoting eyelash growth. Bimatoprost most likely works by interacting with the prostaglandin receptors in the hair follicle and stimulating the resting follicles (telogen phase) to growing follicles (anagen phase). Although bimatoprost is effective in promoting increased growth of healthy eyelashes and adnexal hairs, its effectiveness in patients with eyelash alopecia areata is debatable and its protective effect is not yet studied in patients with eyelash loss secondary to radiation or chemotherapy. Apparently, an intact hair follicle is necessary for exogenous prostaglandin analogs to be effective in the promotion of hair growth.

Bimatoprost is generally safe when applied to the base of the eyelash at the lid margin with minimum side effects including ocular or lid irritation, conjunctiva hyperemia and hyperpigmentaton of the lid. Other ocular or systemic side effects associated with ophthalmic bimatoprost and other prostaglandin analogs when instilled on the surface of the eye should be monitored, and patients must be informed.

Based on the general desire of longer, thicker, and darker eyelashes as a sign of femininity and beauty in most cultures, and the high volume of mascara sales, Latisse ${ }^{\circledR}$ is expected to be a popular alternative for those seeking to augment their lash appearance.

\section{Disclosure}

The author has received honoraria from Allergan Inc.

\section{References}

1. International society of hair restoration surgery. Eyelash transplantation: Who, Why and How. http://www.ishrs.org/articles/ eyelash-transplantation. htm Accessed Nov 30, 2009.

2. Woodson SA. Latisse: empirical discovery yields treatment for sparse eyelashes. Nurs Womens Health. 2009;13:243-248.

3. Pucci N, Novembre E, Lombardi E, et al. Long eyelashes in a case series of 93 children with vernal keratoconjunctivitis. Pediatrics. 2005; 115:1542-1555.

4. Johnstone MA. Hypertrichosis and increased pigmentation of eyelashes and adjacent hair in the region of the ipsilateral eyelids of patients treated with unilateral topical latanoprost. Am J Ophthalmol. 1997;124: 544-547.

5. Wand M. Latanoprost and hyperpigmentation of eyelashes. Arch Ophthalmol. 1997;115:1206-1208.

6. Gandolfi S, Simmons ST, Sturm R, et al. Three-month comparison of bimatoprost and latanoprost in patients with glaucoma and ocular hypertension. Adv Ther. 2001;18:110-121.

7. Noecker RS, Dirks MS, Choplin NT, et al; Bimatoprost/Latanoprost Study Group. A six-month randomized clinical trial comparing the intraocular pressure-lowering efficacy of bimatoprost and lantanoprost in patients with ocular hypertension or glaucoma. Am J Ophthalmol. 2003;135:55-63.
8. Parrish RK, Palmberg P, Sheu WP; XLT Study Group. A comparison of lantaoprost, bimatoprost, and travaprost in patients with elevated intraocular pressure: a 12-week, randomized, masked-evaluator multicenter study. Am J Ophthalmol. 2003;135:688-703.

9. Konstas AG, Katsimbris JM, Lallos N, et al. Latanoprost $0.005 \%$ versus bimatoprost $0.03 \%$ in primary open-angle glaucoma patients. Ophthalmology. 2005;112:262-266.

10. Liotet S, Riera M, Nguyen H. Les cils. Physiologie, structure, pathologie. Arch Ophthalmol. 1977;37:697-708.

11. Na JI, Kwon OS, Kim BK, et al. Ethnic characteristics of eyelashes: a comparative analysis in Asian and Caucasian females. Br J Dermatol. 2006;155:1170-1176.

12. Montagna W, Ford DM, Histology and cytochemistry of human skin. 3. The eyelid. Arch Dermatol. 1969;100:328-335.

13. Thibaut S, De Becker E, Calsey L, et al. Human eyelash characterization. Br J Dermatol. 2009 Sep 1. [Epub ahead of print].

14. Bartosová L. Biology of hair growth. Curr Probl Dermatol. 1984;12:1-58.

15. Johnstone MA, Albert DM. Prostaglandin-induced hair growth. Surv Ophthalmol. 2002;47(Suppl 1):S185-S202.

16. Katz M, Wheeler KE, Radowsky M, Gordon W. Assessment of rate of hair growth using a simple trichometer. Med Biol Eng Comput. 1979;17:333-336.

17. Deplewski D, Rosenfield RL. Role of hormones in pilosebaceous unit development. Endocr Rev. 2000;21:363-392.

18. Elder MJ. Anatomy and physiology of eyelash follicles: relevance to lash ablation procedures. Ophthal Plast Reconstu Surg. 1997;13:21-25.

19. Bläuer M, Vaalasti A, Pauli SL, Ylikomi T, Joensuu T, Tuohimaa P. Location of androgen receptor in human skin. J Invest Dermatol. 1991;97:264-268.

20. Randall VA, Hibberts NA, Thornton MJ, et al. The hair follicle: a paradoxical androgen target organ. Horm Res. 2000;54:243-250.

21. Woodward DF, Krauss AH, Chen J, et al. The pharmacology of bimatoprost (Lumigan). Surv Ophthalmol. 2001;45 Suppl 4:S337-S345.

22. Woodward DF, Krauss AH, Chen J, et al. Pharmacological characterization of a novel antiglaucoma agent, Bimatoprost (AGN 192024). J Pharmacol Exp Ther. 2003;305:772-785.

23. Bisogno T. Endogenous cannabinoids: structure and metabolism. J Neuroendocrinol. 2008;20 Suppl 1:1-9.

24. Alpini G, Demorrow S. Changes in the endocannabinoid system may give insight into new and effective treatments for cancer. Vitam Horm. 2009;81:469-485.

25. Di Marzo V. Endocannabinoids: synthesis and degradation. Rev Physiol Biochem Pharmacol. 2006;160:1-24.

26. Woodward DF, Liang Y, Krauss AH. Prostamides (prostaglandinethanolamides) and their pharmacology. Br J Pharmacol. 2008;153: 410-419.

27. Liang Y, Woodward DF, Guzman VM, et al. Identification and pharmacological characterization of the prostaglandin FP receptor and FP receptor variant complexes. Br J Pharmacol. 2008;154:1079-1093.

28. Colombe L, Vindios A, Michelet JF, Bernard BA. Prostaglandin metabolism in human hair follicle. Exp Dermatol. 2007;16:762-769.

29. Colombe L, Michelet JF, Bernard BA. Prostanoid receptors in anagen human hair follicles. Exp Dermatol. 2008;17:63-72.

30. Torii E, Segi E, Sugimoto Y, et al. Expression of prostaglandin E92 receptor subtypes in mouse hair follicles. Biochem Biophys Res Comm. 2002;290:696-700.

31. Rosenigk HH Jr. New topical agents for hair growth. Clin Dermatol. 1988;6:119-121.

32. Meyer HC. Alopecia associated with ibuprofen. JAMA. 1979: 242:142.

33. Pillans PI, Woods DJ. Drug-associated alopecia. Int $J$ Dermatol. 1995;34:149-158

34. Michelet JF, Commo S, Billoni N, Mahe YF, Bernard BA. Activation of ytoprotective prostaglandin synthase-1 by minoxidil as a possible explanation for its hair growth-stimulating effect. $J$ Invest Dermatol. 1997;108:205-209. 
35. Stjernschantz JW. From PGF (2alpha)-isopropyl ester to lantaoprost: a review of the development of xalatan: the Proctor Lecture. Invest Ophthalmol Vis Sci. 2001;42:1134-1145.

36. Sasaki S, Hozumi Y, Kondo S. Influence of prostaglandin F2 $\alpha$ and its analogues on hair regrowth and follicular melanogenesis in a murine model. Exp Dermatol. 2005;14:323-328.

37. Uno H, Zimbric ML, Albert DM, Stjernschantz J. Effect of latanoprost on hair growth in the bald scalp of the stump-tailed macaque: a pilot study. Acta Derm Venereol. 2002;82:7-12.

38. Burnett JW, Harvey VM. Circumscribed palmar or plantar hypokeratosis: report of two additional cases. $J$ Am Acad Dermatol. 2004;51:843-844.

39. Paus R, Cotsarelis G. The biology of hair follicles. $N$ Engl J Med. 1999;341:491-497.

40. Demitsu T, Manabe M, Harima N, Sugiyama T, Yoneda K, Yamada N. Hypertrichosis induced by lantanoprost. J Am Acad Dermatol. 2001;44:721-723.

41. Inouye K, Wakakura M, Inoue J, Matsuo H, Hara T, Tomita G. Adverse reaction after use of latanoprost in Japanese glaucoma patients. Nippon Ganka Gakkai Zasshi. 2006;110:581-587.

42. Elgin U, Batman A, Becker N, Iihan B. The comparison of eyelash lengthening effect of latanoprost therapy in adults and children. Eur J Ophthalmol. 2006;16:247-250.

43. Netland PA, Landry T, Sullivan EK, et al. Travoprost compared with latanoprost and timolol in patients with open angle glaucoma or ocular hypertension. Am J Ophthalmol. 2001;132:472-484.

44. Sherwood M, Brandt J; Bimatoprost Study Groups 1 and 2. Six-month comparison of bimatoprost once-daily and twice-daily with timolol twice-daily in patients with elevated intraocular pressure. Surv Ophthalmol. 2001;45 Suppl 4:S361-S368.

45. Brandt JD, VanDenburgh AM, Chen K, et al. Bimatoprost Study Group. Comparison of once- or twice-daily bimatoprost with twice-daily timolol in patients with elevated IOP: a 3-month clinical trial. Ophthalmology. 2001;108:1023-1031.

46. Food and Drug Administration, Division of Anti-infective and Ophthalmology Products Advisory Committee. Briefing information: bimatoprost ophthalmic solution for the treatment of hypotrichosis of the eyelashes. http:/www.fda.gov/ohrms/dockets/ ac/08/briefing/2008-4397b1-03-FDA.pdf. Accessed Nov 30, 2009.

47. Chen CS, Wells J, Craig JE. Topical prostaglandin F2 analog induced poliosis. Am J Ophthalmol. 2004;137:965-966.

48. Zaheri S. Hughes B. Successful use of bimatoprost in the treatment of alopecia of the eyelashes. Clin Exp Dermatol. 2009 Nov 19. [Epub ahead of print].

49. Ochoa BE, Sah D, Wang G, Stamper R, Price VH. Instilled bimatoprost ophthalmic solution in patients with eyelash alopecia areata. J Am Acad Dermatol. 2009;61:530-532.

50. Mansberger SL, Cioffi GA. Eyelash formation secondary to latanoprost treatment in a patient with alopecia. Arch Ophthalmol. 2000;118: 718-719.

51. Mehta JS, Raman J, Gupta N, Thoung D. Cutaneous latanoprost in the treatment of alopecia areata. Eye. 2003;17:444-446.

52. Roseborough I, Lee H, Chwalek J, Stamper RL, Price VH. J Am Acad Dermatol. 2009;60:705-706

53. Feletti F, Vincenzi C, Pazzaglia M, Tosti A. Periocular pigmentation associated with use of travoprost for the treatment of alopecia areata of the eyelashes. J Eur Acad Dermatol Venereol. 2007;21:421-423.

54. Geng L, Hanson WR, Malkinson FD. Topical or systemic 16, 16 dm prostaglandin E2 or WR-2721 (WR-1065) protects mice from alopecia after fractionated irradiation. Int J Radiat Biol. 1992;61:533-537.

55. Hanson wR, Pelka AE, Nelson AK, Malkinson FD. Subcutaneous or topical administration of 16, 16 dimethyl prostaglandin E2 protects from radiation-induced alopecia in mice. Int J Radiat Oncol Biol Phys. 1992;23:333-337.

56. Malkinson FD, Geng L, Hanson WR. Prostaglandins protect against murine hair injury produced by ionizing radiation or doxorubicin. J Invest Dermatol. 1993;101:135S-137S.
57. Cracknell KP, Grierson I, Hogg P, Appleton P, Pfeiffer N. Latanoprost-induced iris darkening: a morphometric study of human peripheral iridectomies. Exp Eye Res. 2003;77:721-730.

58. Cracknell KP, Farnell DJ, Grierson I. Monte Carlo simulation of latanoprost induced iris darkening. Comput Methods Programs Biomed. 2007;87:93-103

59. Arranz-Marquez E, Teus MA. Effect of age on the development of a latanoprost-induced increase in iris pigmentation. Ophthalmology. 2007;114:1255-1258.

60. Wistrand PJ, Stjernschantz J, Olsson K. The incidence and time-course of latanoprost-induced iridial pigmentation as a function of eye color. Surv Ophthalmol. 1997;41(Suppl 2):S129-S138.

61. Stewart WC, Kolker AE, Stewart JA, et al. Conjunctival hyperemia in healthy subjects after short-term dosing with latanoprost, bimatoprost, and travoprost. Am J Ophthalmol. 2003;135:314-320.

62. Weston BC. Migraine headache associated with latanoprost. Arch Ophthalmol. 2001;119:300-301.

63. Kapur R, Osmanovic S, Toyran S, Edward DP. Bimatoprost-induced periocular skin hyperpigmentation: histopathological study. Arch Ophthalmol. 2005;123:1541-1546.

64. Centofanti M, Oddone F, Chimenti S, Tanga L, Citarella L, Manni G. Prevention of dermatologic side effects of bimatoprost $0.03 \%$ topical therapy. Am J Ophthalmol. 2006;142:1059-1060.

65. Peplinski LS, Albiani Smith K. Deepening of lid sulcus from topical bimatoprost therapy. Optom Vis Sci. 2004;81:574-577.

66. Tappeiner C, Perren B, Iliev ME, Frueh BE, Goldblum D. Orbital fat atrophy in glaucoma patients treated with topical bimatoprostcan bimatoprost cause enophthalmos? Klin Monbl Augenheilkd. 2008;225:443-445.

67. Filippopoulos T, Paula JS, Torun N, Hatton MP, Pasquale LR, Grosskreutz CL. Periorbital changes associated with topical bimatoprost. Ophthal Plast Reconstr Surg. 2008;24:302-307.

68. Yang HK, Park KH, Kim TW, Kim DM. Deepening of eyelid superior sulcus during topical travoprost treatment. Jpn J Ophthalmol. 2009;53:176-179.

69. Packer M, Fine IH, Hoffman RS. Bilateral nongranulomatous anterior uveitis associated with bimatoprost. J Cataract Refract Surg. 2003;29:2242-2243.

70. Parentin F. Granulomatous anterior uveitis associated with bimatoprost: a case report. Ocul Immunol Inflamm. 2003;11:67-71.

71. Smith SL, Pruitt CA, Sine CS, et al. Latanoprost $0.005 \%$ and anterior segment uveitis. Acta Ophthalmol Scand. 1999;77:668-672.

72. Warwar RE, Bullock JD, Ballal D. Cystoid macular edema and anterior uveitis associated with latanoprost use. Experience and incidence in a retrospective review of 94 patients. Ophthalmology. 1998;105:263.

73. Fechtner RD, Khouri AS, Zimmerman TJ, et al. Anterior uveitis associated with latanoprost. Am J Ophthalmol. 1998;126:37-41.

74. Kroll DM, Schuman JS. Reactivation of herpes simplex virus keratitis after initiating bimatoprost treatment for glaucoma. Am J Ophthalmol. 2002;133:401-403.

75. Kothari MT, Mehta BK, Asher NS, Kothari KJ. Recurrence of bilateral herpes simplex virus keratitis following bimatoprost use. Indian J Ophthalmol. 2006;54:47-48.

76. Wand M, Gilbert CM, Liesegang TJ. Latanoprost and herpes simplex keratitis. Am J Ophthalmol. 1999;127:602-604.

77. Morales J, Shihab ZM, Brown SM, et al. Herpes simplex virus dermatitis in patients using latanoprost. Am J Ophthalmol. 2001;132:114-116.

78. Kaufman HE, Varnell ED, Thompson HW. Latanprost increases the severity and recurrence of herpetic keratitis in the rabbit. Am J Ophthalmol. 1999;127:531-536.

79. Gordon YJ, Yates KA, Mah FS, et al. The effects of Xalatan on the recovery of ocular herpes simplex virus type 1 (HSV-1) in the induced reactivation and spontaneous shedding rabbit models. J Ocul Pharmacol Ther. 2003;19:233-245.

80. Hempstead N, Hempstead RW. Unilateral trichomegaly induced by bimatoprost ophthalmic solution. J Drugs Dermatol. 2004;3: $571-572$. 
81. Herane MI, Urbina F. Acquired trichomegaly of the eyelashes, and hypertrichosis induced by bimatoprost. J Eur Acad Dermatol Venereol. 2004;18:644-645.

82. Hart J. Shafranov G. Hypertrichosis of vellus hairs of the malar region after unilateral treatment with bimatoprost. Am J Ophthalmol. 2004;137:756-757.

83. Bearden W, Anderson R. Trichiasis associated with prostaglandin analog use. Ophthal Plast Reconstr Surg. 2004;20(4):320-322.

84. Casson RJ, Selva D. Lash ptosis caused by latanoprost. Am JOphthalmol. 2005;139:932-933.

85. Doshi M, Edward DP, Osmanovic S. Clinical course of bimatoprostinduced periocular skin changes in Caucasians. Ophthalmology. 2006;113:1961-1967.

86. Herndon LW, Williams RD, Wand M, Asrani S. Increased periocular pigmentation with ocular hypotensice lipid use in African Americans. Am J Ophthalmol. 2003;135:713-715.

87. Baudouin C, Riancho L, Warnet JM, Brignole F. In vitro studies of antiglaucomatous prostaglandin analogues: travoprost with and without benzalkonium chloride and preserved latanoprost. Invest Ophthalmol Vis Sci. 2007;48:4123-4128.
88. Carrillo MM, Nicolela MT. Cystoid macular edema in a low-risk patient after switching from latanoprost to bimatoprost. Am J Ophthalmol. 2004;137:966-968.

89. Laibovitz RA, VanDenburgh AM, Felix C, et al. Comparison of the ocular hypotensive lipid AGN 192024 with timolol: dosing, efficacy, and safety evaluation of a novel compound for glaucoma management. Arch Ophthalmol. 2001;119:994-1000.

90. Dubiner H, Cooke D, Dirks M, et al. Efficacy and safety of bimatoprost in patients with elevated intraocular pressure: a 30-day comparison with latanoprost. Surv Ophthalmol. 2001;45(Suppl 4):S353-S360.

91. Lee YC. Abdominal cramp as an adverse effect of travoprost. Am J Ophthalmol. 2005;139:202-203.

92. Mitra M, Chang B, James T. Drug points. Exacerbation of angina associated with latanoprost. BMJ. 2001;323:783.

93. Peak AS, Sutton BM. Systemic adverse effects associated with topically applied latanoprost. Ann Pharmacother. 1998;32:504-505.

94. De Santis M, Lucchese A, Carducci B, et al. Latanoprost exposure in pregnancy. Am J Ophthalmol. 2004;138:305-306.
Clinical Ophthalmology

\section{Publish your work in this journal}

Clinical Ophthalmology is an international, peer-reviewed journal covering all subspecialties within ophthalmology. Key topics include: Optometry; Visual science; Pharmacology and drug therapy in eye diseases; Basic Sciences; Primary and Secondary eye care; Patient Safety and Quality of Care Improvements. This journal is indexed on

\section{Dovepress}

PubMed Central and CAS, and is the official journal of The Society of Clinical Ophthalmology (SCO). The manuscript management system is completely online and includes a very quick and fair peer-review system, which is all easy to use. Visit http://www.dovepress.com/ testimonials.php to read real quotes from published authors. 